\title{
Eine Tagesdosis »Bedeutung für andere«
}

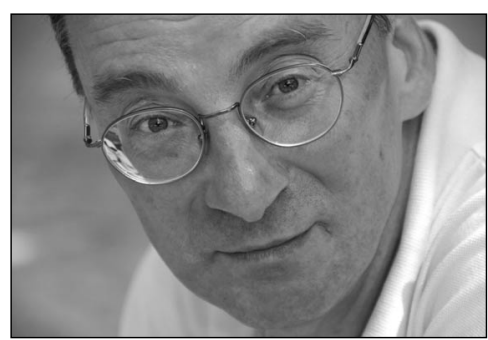

Foto: Petra Schmucker, Frankfurt am Main
Viele Menschen engagieren sich freiwillig in sozialen Diensten und Einrichtungen. Sie kümmern sich um Kinder, die in der Schule mehr gefordert als gefördert werden, um Jugendliche ohne Lehrstelle, um kranke, behinderte, obdachlose und überschuldete Erwachsene.

Freiwilligen geht es in erster Linie darum, diesen Menschen zu helfen. Soziale Träger tun gut daran, sich intensiv und professionell um die dafür erforderlichen organisatorischen Rahmenbedingungen zu kümmern. Ohne Freiwillige, so Walter Häcker und Doris Knaier in ihrem Beitrag in diesem Heft, würden die Kosten in vielen Einrichtungen explodieren, viele benachteiligte Menschen würden eine glaubwürdige Lobby verlieren und das soziale Klima würde kalt und rau. Zudem »rechnet « sich der Einsatz der Freiwilligen, wie die Autoren in einer Studie belegen: Jeder Euro, der für die Förderung des Ehrenamts eingesetzt wird, bringt eine Wertschöpfung von sechs bis sieben Euro (vgl. Seite 22).

Die Verantwortlichen sozialer Organisationen tun also gut daran, sich über ihr Freiwilligen-Management Gedanken zu machen. Die Ehrenamtlichen sind in zu vielen Diensten und Einrichtungen bislang eher akzeptiert als gewollt, wie Doris Rosenkranz und Jürgen Schill in ihrem Beitrag kritisieren. Künftig werde aus den Freiwilligen jedoch, ökonomisch betrachtet, schon aus demografischen Gründen ein knappes und begehrtes Gut, um das mehrere Dienstleister werben würden.

Die Autorinnen und Autoren in diesem Heft zeigen Wege, wie der Einsatz Ehrenamtlicher organisiert werden kann, welche Strukturen förderlich, welche hinderlich sind. Nicht vergessen werden sollte dabei, dass Menschen, die sich engagieren wollen, auch ein Stück Heimat, ein bisschen Nestwärme suchen. Auch Freiwillige brauchen legitimerweise, wie alle Menschen, eine Tagesdosis an Bedeutung für andere Menschen, wie es Klaus Dörner einmal ausgedrückt hat.

\section{Sozialmanagement}

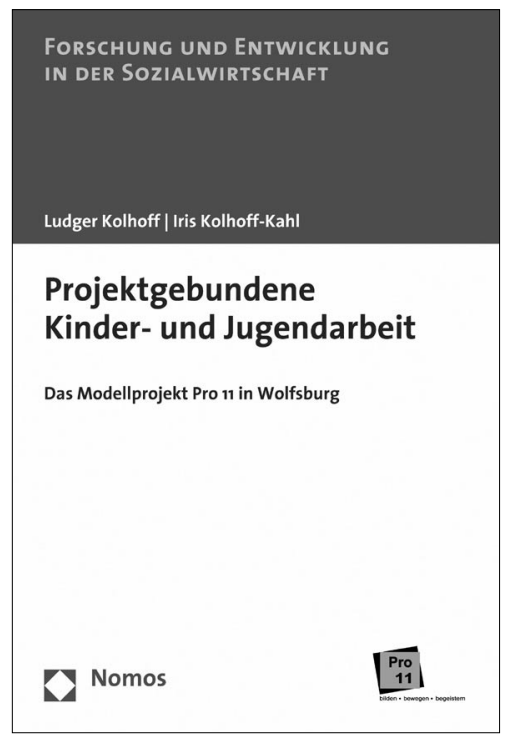

\section{Projektgebundene Kinder- und Jugendarbeit}

Das Modellprojekt Pro 11 in Wolfsburg

Von Prof. Dr. Ludger Kolhoff und

Prof. Dr. Iris Kolhoff-Kahl

2009, 135 S., brosch., 24,- $€$,

ISBN 978-3-8329-3733-1

(Forschung und Entwicklung

in der Sozialwirtschaft, Bd. 5)

Die offene Kinder- und Jugendarbeit "Pro 11" in Wolfsburg wurde von einem Organisationsentwicklungsprozess begleitet. Der Band analysiert und interpretiert den gesamten Prozess und stellt positive wie negative Erfahrungen vor. Es wird gezeigt, wie Theoriekonzepte und Praxisumsetzungen wiederum neue überraschende Handlungs- und Denkoptionen eröffnen. Ein Buch für alle, die sich mit Sozialmanagement befassen.

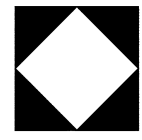

Nomos 